\title{
DELAY-DEPENDENT ASYMPTOTIC STABILITY FOR NEURAL NETWORKS WITH TIME-VARYING DELAYS
}

\author{
XIAOFENG LIAO, XIAOFAN YANG, AND WEI ZHANG
}

Received 3 August 2005; Accepted 6 November 2005

We study the dynamical behavior of a class of neural network models with time-varying delays. By constructing suitable Lyapunov functionals, we obtain sufficient delay-dependent criteria to ensure local and global asymptotic stability of the equilibrium of the neural network. Our results are applied to a two-neuron system with delayed connections between neurons, and some novel asymptotic stability criteria are also derived. The obtained conditions are shown to be less conservative and restrictive than those reported in the known literature. Some numerical examples are included to demonstrate our results.

Copyright (c) 2006 Xiaofeng Liao et al. This is an open access article distributed under the Creative Commons Attribution License, which permits unrestricted use, distribution, and reproduction in any medium, provided the original work is properly cited.

\section{Introduction}

An artificial neural network model is usually described by a system of ordinary differential equations. But experimental studies have demonstrated that, in general, time delays exist in electronic circuits because of the finite switching speed of amplifiers and the model should be described by the system of delay differential equations. Therefore, theoretical and computational studies of the dynamical system for the Hopfield-type analog neural network with time delays have advanced greatly in the recent years (see, e.g., $[5,7-9,11-13,16,17,19-22]$ and the references therein). It is well known that the effects of time delays on dynamical properties of neural networks are very complicated. If the connection matrix is symmetric or antisymmetric, Hopfield-type neural network without time delays is always either a convergent gradient networks or a stable network, respectively. However, if the delays are present, their convergences and stability properties may be lost even for very small delays, and oscillations or chaos may occur (see, e.g., $[1,14,15,18,21])$.

On the other hand, it is also known that delays may lead to increased stability for some dynamical systems $[2,4,22]$. The existence of equilibria of neural networks is studied in 
$[3,7-9,11-13,16,17,19,20,22]$. Detailed analysis of local stability (or, the so-called linear stability) of equilibria, oscillation, and existence of periodic solutions for some models simpler than neural network model (e.g., ring neural network models) is presented in $[1,14,15,18,21]$, based on the classical methods of characteristic equations and Hopf bifurcation analysis (see $[10,14,15,18]$ ) and numerical computations.

Global asymptotic stability of the equilibrium of neural network with time delays, which is more important and usually more difficult to analyze than local stability, is investigated in $[7-13,16,17,19,20,22]$ by Lyapunov functions. The results in $[3,6-$ $9,11-20,22]$ essentially say that if the gains of the activation functions or the synaptic connection strength are small enough, the network is globally asymptotically stable independent on the delay. Global asymptotic stability of the equilibrium of a class of delayed Hopfield-type ring neural network model which satisfies positive feedback condition is also considered in [21], and a very general sufficient criterion for global asymptotic stability of equilibrium is given based on the properties of monotone semidynamical system $[4,22]$.

However, in many practical time-delay neural networks, the time delays appearing in the systems are time-varying or are only known to be bounded in a certain range. Typical time-delay neural networks with multiple time-varying delays include the Hopfield neural network model $[7-9,12,16,19,22]$, cellular neural network model $[12,17,20]$, and bi-directional associative memory $[3,13]$. Consequently, the stability analysis of timedelay systems has been a main concern of researchers. The stability criteria for timedelay systems can be classified into two categories, namely, delay-independent criteria and delay-dependent criteria, depending on whether they contain the delay argument as a parameter. There have been a number of significant developments in searching the stability criteria for systems with constant delays. However, the criteria are mostly delayindependent ones for time-delay systems with constant delays $[3,6-9,11-13,16,17,19$, $20,22]$ and only a few of them are for neural networks with time-varying delays, see, for example, $[7,8,11,12]$.

In this paper, we will give some new criteria for local and global asymptotic stability of the equilibrium of neural networks with time-varying delays. Our results essentially show that if the equilbirum of the network remains globally asymptotically stable when time delays are small enough, suitable Lyapunov functionals are constructed to prove our results.

The organization of this paper is as follows. In the following section, we will give the network system to be considered and some needed preliminaries. The proofs of the main results will be given in Section 3. In Section 4, we apply our results to two-neuron system with time delays and numerical simulations to illustrate the applications of our results. Some conclusions are also given in Section 5. Finally, we will give the detailed constructive procedure of the Lyapunov functional $V$ used in Appendix A. 


\section{Statement of networks and preliminaries}

In this paper, we will consider the following neural networks with time-varying delays:

$$
\begin{aligned}
\dot{u}_{i}(t)= & -d_{i}\left(u_{i}(t)\right)+\sum_{j=1}^{n} w_{i j} g_{j}\left(u_{j}(t)\right) \\
& +\sum_{j=1}^{n} w_{i j}^{\tau} g_{j}\left(u_{j}\left(t-\tau_{i j}(t)\right)\right)+I_{i}, \quad i=1,2, \ldots, n,
\end{aligned}
$$

for $t \geq 0$, where $w_{i j}, w_{i j}^{\tau}$, and $I_{i}$ are real constants. The delays $\tau_{i j}(t)$ are more than zeros. The functions $g_{j}$ are continuously differentiable on $R=(-\infty,+\infty)$ and such that $g_{j}(0)=$ $0, j=1,2, \ldots, n$.

For system (2.1), we assume that the following conditions are satisfied.

$\left(\mathrm{H}_{1}\right)$ There exist positive constants $\underline{D}_{i}$ and $\bar{D}_{i}, i=1,2, \ldots, n$, such that, for all arguments,

$$
0<\underline{D}_{i} \leq \frac{d_{i}\left(x_{i}\right)-d_{i}\left(y_{i}\right)}{x_{i}-y_{i}} \leq \bar{D}_{i}, \quad \text { for } x_{i} \neq y_{i}, i=1,2, \ldots, n
$$

$\left(\mathrm{H}_{2}\right) g_{j}, j=1,2, \ldots, n$, are bounded on $\mathbb{R}$, that is, there exist positive constants, $G_{j}$, $j=1,2, \ldots, n$, such that for any $w \in R$,

$$
\left|g_{j}(w)\right| \leq G_{j}, \quad j=1,2, \ldots, n
$$

$\left(\mathrm{H}_{3}\right)$ For any $w \in R, g_{j}^{\prime}(w)>0, j=1,2, \ldots, n$.

$\left(\mathrm{H}_{4}\right) \tau_{i j}:[0,+\infty) \rightarrow[0,+\infty)$ is continuous and $0 \leq \tau_{i j}(t) \leq \bar{\tau}$.

The initial condition for (2.1) is given as follows:

$$
u_{j}(s)=\phi_{j}(s), \quad s \in[-\bar{\tau}, 0]
$$

where $\phi_{j}(s), j=1,2, \ldots, n$, are continuous on $[-\bar{\tau}, 0]$.

It is not difficult to show that under $\left(\mathrm{H}_{1}\right)-\left(\mathrm{H}_{4}\right)$, the solution of (2.1) satisfying the above initial condition exists on $R_{+} \equiv[0,+\infty)$ (see, e.g., $[2,4,12]$ ). In fact, note that from Lemma 2.1 below, it is clear that the solution of (2.1) is also unique.

It is also easy to show that $(2.1)$ has always an equilibrium $u_{j}^{*}, j=1,2, \ldots, n$. That is, there exist $u_{j}^{*}, j=1,2, \ldots, n$, such that

$$
d_{i}\left(u_{i}^{*}\right)=\sum_{j=1}^{n}\left(w_{i j}+w_{i j}^{\tau}\right) g_{j}\left(u_{j}^{*}\right)+I_{i}, \quad i=1,2, \ldots, n .
$$

By using the strict monotonicity property of $d_{i}$, there exist positive numbers $\bar{d}_{i}>0$ such that

$$
d_{i}\left(u_{i}^{*}\right)=\bar{d}_{i} u_{i}^{*}, \quad i=1,2, \ldots, n .
$$


4 Delay-dependent asymptotic stability

Hence,

$$
u_{i}^{*}=\bar{d}_{i}^{-1}\left\{\sum_{j=1}^{n}\left(w_{i j}+w_{i j}^{\tau}\right) g_{j}\left(u_{j}^{*}\right)+I_{i}\right\}, \quad i=1,2, \ldots, n .
$$

In fact, let us consider the map $P=\left(P_{1}, P_{2}, \ldots, P_{n}\right)$ on the compact convex set $\Omega$, where

$$
\begin{gathered}
P_{i}\left(u_{1}, u_{2}, \ldots, u_{n}\right)=\bar{d}_{i}^{-1}\left\{\sum_{j=1}^{n}\left(w_{i j}+w_{i j}^{\tau}\right) g_{j}\left(u_{j}^{*}\right)+I_{i}\right\}, \quad i=1,2, \ldots, n, \\
\Omega=\left\{\left(u_{1}, u_{2}, \ldots, u_{n}\right)|| u_{i} \mid \leq N_{i 0}\right\} \\
N_{i 0}=\frac{\sum_{j=1}^{n}\left|w_{i j}+w_{i j}^{\tau}\right| G_{j}+\left|I_{i}\right|}{\left|\bar{d}_{i}\right|}, \quad i=1,2, \ldots, n .
\end{gathered}
$$

It follows from $\left(\mathrm{H}_{1}\right)$ and $\left(\mathrm{H}_{2}\right)$ that $P$ is a continuous map which maps $\Omega$ into itself. Thus, it follows from Brouwer's fixed point theorem (see, e.g., $[2,4])$ that $P$ has at least one fixed point $\left(u_{1}^{*}, u_{2}^{*}, \ldots, u_{n}^{*}\right)$ in $\Omega$, that is,

$$
\left(u_{1}^{*}, u_{2}^{*}, \ldots, u_{n}^{*}\right)=P\left(u_{1}^{*}, u_{2}^{*}, \ldots, u_{n}^{*}\right) .
$$

This shows that $\left(u_{1}^{*}, u_{2}^{*}, \ldots, u_{n}^{*}\right)$ satisfies $(2.5)$.

The following lemma is useful in our discussion below.

LEMMA 2.1. If $\left(\mathrm{H}_{1}\right)-\left(\mathrm{H}_{4}\right)$ are satisfied, then for any solution of (2.1),

$$
\limsup _{t \rightarrow \infty}\left|u_{i}(t)\right| \leq N_{i}\left(\leq N_{i 0}\right), \quad i=1,2, \ldots, n,
$$

where the positive constants $N_{i}, i=1,2, \ldots, n$, satisfy

$$
\begin{gathered}
N_{i}=\frac{\sum_{j=1}^{n}\left|w_{i j}+w_{i j}^{\tau}\right| \bar{g}_{i}\left(N_{i}\right)+\left|I_{i}\right|}{\left|\bar{d}_{i}\right|}, \\
\bar{g}_{i}\left(N_{i}\right)=\max \left\{g_{i}\left(N_{i}\right),-g_{i}\left(-N_{i}\right)\right\}, \quad i=1,2, \ldots, n .
\end{gathered}
$$

Proof. It is clear from $\left(\mathrm{H}_{1}\right)-\left(\mathrm{H}_{4}\right)$ and (2.1) that

$$
\limsup _{t \rightarrow \infty}\left|u_{i}(t)\right| \leq N_{i 0}, \quad i=1,2, \ldots, n .
$$

Thus, for sufficiently small $\eta>0$ and sufficiently large $T_{0}>0$, such that for $t \geq T_{0}$,

$$
\left|u_{i}(t-\tau)\right| \leq N_{i 0}+\eta, \quad i=1,2, \ldots, n,
$$

which, together with $\left(\mathrm{H}_{3}\right)$ and (2.1), yields that, for $t \geq T_{0}$,

$$
\dot{u}_{i}(t) \leq-\left|d_{i}\left(u_{i}(t)\right)\right|+\sum_{j=1}^{n}\left(\left|w_{i j}+w_{i j}^{\tau}\right|\right) \bar{g}_{j}\left(N_{i 0}+\eta\right)+\left|I_{i}\right|, \quad i=1,2, \ldots, n .
$$


Note that, one can take $\eta \rightarrow 0$ as $t \rightarrow+\infty$. We have

$$
\limsup _{t \rightarrow \infty}\left|u_{i}(t)\right| \leq N_{i 1}, \quad i=1,2, \ldots, n,
$$

where

$$
N_{i 1}=\frac{\sum_{j=1}^{n}\left(\left|w_{i j}+w_{i j}^{\tau}\right|\right) \bar{g}_{i}\left(N_{i 0}\right)+\left|I_{i}\right|}{\left|\bar{d}_{i}\right|} \leq N_{i 0}, \quad i=1,2, \ldots, n .
$$

By repeating the above procedure, we can obtain positive sequences $\left\{N_{i, k}\right\}$ such that

$$
\begin{gathered}
N_{i, k+1}=\frac{\sum_{j=1}^{n}\left(\left|w_{i j}+w_{i j}^{\tau}\right|\right) \bar{g}_{i}\left(N_{i, k}\right)+\left|I_{i}\right|}{\left|\bar{d}_{i}\right|} \leq N_{i, k}, \quad i=1,2, \ldots, n, \\
\limsup _{t \rightarrow \infty}\left|u_{i}(t)\right| \leq N_{i, k}, \quad i=1,2, \ldots, n, k=0,1,2, \ldots .
\end{gathered}
$$

Let $N_{i}$ denote the limits of $\left\{N_{i, k}\right\}$ as $\mathrm{k} \rightarrow+\infty$, respectively. Then, we have

$$
\begin{gathered}
N_{i}=\left\{\frac{\sum_{j=1}^{n}\left(\left|w_{i j}+w_{i j}^{\tau}\right|\right) \bar{g}_{i}\left(N_{i, k}\right)+\left|I_{i}\right|}{\left|\bar{d}_{i}\right|}\right\}, \quad i=1,2, \ldots, n, \\
\limsup _{t \rightarrow \infty}\left|u_{i}(t)\right| \leq N_{i} .
\end{gathered}
$$

This shows that Lemma 2.1 is true.

By Lemma 2.1, we see that for any sufficiently small positive constant $\varepsilon$, there exists a sufficiently large time, $T=T(\varepsilon)>0$, such that for $t \geq T$,

$$
\left|u_{i}(t)\right| \leq N_{i}+\varepsilon, \quad i=1,2, \ldots, n .
$$

Define the positive constants $p_{i \varepsilon}$ and $q_{i \varepsilon}, i=1,2, \ldots, n$, as follows:

$$
p_{i \varepsilon} \equiv \min _{-\left(N_{i}+\varepsilon\right) \leq w \leq N_{i}+\varepsilon} g_{i}^{\prime}(w) \leq \max _{-\left(N_{i}+\varepsilon\right) \leq w \leq N_{i}+\varepsilon} g_{i}^{\prime}(w) \equiv q_{i \varepsilon}, \quad i=1,2, \ldots, n .
$$

Let $p_{i}$ and $q_{i}, i=1,2, \ldots, n$, denote the limits of $p_{i \varepsilon}$ and $q_{i \varepsilon}$, respectively, as $\varepsilon \rightarrow 0$.

Remark 2.2. It is not difficult to show that the equilibrium $\left(u_{1}^{*}, u_{2}^{*}, \ldots, u_{n}^{*}\right)$ of $(2.1)$ is also unique if $\left(\mathrm{H}_{1}\right)-\left(\mathrm{H}_{4}\right)$ and the following $\left(\mathrm{H}_{5}\right)$ are satisfied.

The following well-known Barbalat lemma (see, e.g., [2]) will also be used.

Lemma 2.3. Let $f$ be a nonnegative function defined on $R_{+}$such that $f$ is integrable and uniformly continuous on $R_{+}$. Then $\lim _{t \rightarrow+\infty} f(t)=0$.

\section{Stability analysis}

In this section, we will consider the stability of the equilibrium $\left(u_{1}^{*}, u_{2}^{*}, \ldots, u_{n}^{*}\right)$ of system (2.1).

Let us first consider the cases $w_{i j}^{\tau} \neq 0$, for some $i, j=1,2, \ldots, n$. We further assume the following hypothesis $\left(\mathrm{H}_{5}\right)$. 
$\left(\mathrm{H}_{5}\right)$ There exist positive constants $\lambda_{i}, i=1,2, \ldots, n$, such that the following matrix:

$$
R=\left(\begin{array}{ccc}
\eta_{1} & r_{12} & r_{13} \cdots r_{1 n} \\
r_{21} & \eta_{2} & r_{23} \cdots r_{2 n} \\
\cdots & \cdots & \cdots \\
r_{n 1} & r_{n 2} & r_{n 3} \cdots \eta_{n}
\end{array}\right)
$$

is negative definite, that is,

$$
(-1)^{i}\left(\begin{array}{ccc}
\eta_{1} & r_{12} & r_{13} \cdots r_{1 n} \\
r_{21} & \eta_{2} & r_{23} \cdots r_{2 n} \\
\cdots & \cdots & \cdots \\
r_{n 1} & r_{n 2} & r_{n 3} \cdots \eta_{n}
\end{array}\right)>0, \quad i=1,2, \ldots, n
$$

where

$$
\begin{aligned}
& \eta_{i}= \lambda_{i}\left(-\frac{D_{i}}{q_{i}}+w_{i i}+w_{i i}^{\tau}\right)+\frac{1}{2} \sum_{j=1}^{n}\left[\left(\frac{\lambda_{i} q_{j} \bar{D}_{j}}{p_{j}}\left|w_{i j}^{\tau}\right| \tau_{i j}(t)+\frac{\lambda_{j} q_{i} \bar{D}_{i}}{p_{i}}\left|w_{j i}^{\tau}\right| \tau_{j i}(t)\right)\right] \\
&+ \frac{1}{2} \sum_{j=1}^{n}\left[\lambda_{i} q_{j} \tau_{i j}(t)\left|w_{i j}^{\tau}\right| \sum_{k=1}^{n}\left(\left|w_{j k}\right|+\left|w_{j k}^{\tau}\right|\right)\right. \\
&\left.+\sum_{k=1}^{n} \lambda_{k} q_{j} \tau_{k j}(t)\left|w_{k j}^{\tau}\right|\left(\left|w_{j k}\right|+\left|w_{j k}^{\tau}\right|\right)\right], \quad i=1,2, \ldots, n, \\
& r_{i j}=\frac{1}{2}\left\{\lambda_{i}\left(w_{i j}+w_{i j}^{\tau}\right)+\lambda_{j}\left(w_{j i}+w_{j i}^{\tau}\right)\right\}, \quad i \neq j, i, j=1,2, \ldots, n .
\end{aligned}
$$

Hence, the equilibrium $\left(u_{1}^{*}, u_{2}^{*}, \ldots, u_{n}^{*}\right)$ of $(2.1)$ is unique.

Theorem 3.1. If $w_{i j}^{\tau} \neq 0$, for some $i, j=1,2, \ldots, n$, and $\left(\mathrm{H}_{1}\right)-\left(\mathrm{H}_{5}\right)$ are satisfied, then the equilibrium $\left(u_{1}^{*}, u_{2}^{*}, \ldots, u_{n}^{*}\right)$ of system $(2.1)$ is globally asymptotically stable.

Proof. As usual, let us set

$$
\begin{gathered}
x_{j}(t)=u_{j}(t)-u_{j}^{*}, \quad j=1,2, \ldots, n, \\
f_{j}\left(x_{j}(t)\right)=g_{j}\left(x_{j}(t)+u_{j}^{*}\right)-g_{j}\left(u_{j}^{*}\right), \quad j=1,2, \ldots, n, \\
h_{j}\left(x_{j}(t)\right)=d_{j}\left(x_{j}(t)+u_{j}^{*}\right)-d_{j}\left(u_{j}^{*}\right), \quad j=1,2, \ldots, n .
\end{gathered}
$$


Then, the stability properties of the equilibrium $\left(u_{1}^{*}, u_{2}^{*}, \ldots, u_{n}^{*}\right)$ of $(2.1)$ are equivalent to that of the trivial solution of the following system:

$$
\dot{x}_{i}(t)=-h_{i}\left(x_{i}(t)\right)+\sum_{j=1}^{n} w_{i j} f_{j}\left(x_{j}(t)\right)+\sum_{j=1}^{n} w_{i j}^{\tau} f_{j}\left(x_{j}\left(t-\tau_{i j}(t)\right)\right) .
$$

It follows from Appendix A that there exists a Lyapunov functional $V=V\left(x_{t}\right) \geq 0$ such that the upper right derivative $D^{+} V$ of $V$ along the solutions (3.5) satisfies

$$
\left.D^{+} V\right|_{(3.5)} \leq-\delta(\varepsilon) \sum_{j=1}^{n} f_{j}^{2}\left(x_{j}(t)\right)
$$

for $t \geq T+\bar{\tau}$. Here $\delta(\varepsilon)>0$ is some constant. $x_{t}=x(t+s)$ for $-\bar{\tau} \leq s \leq 0$.

Integrating (3.6) over $[T+\bar{\tau}, t]$ yields

$$
V\left(x_{t}\right)+\delta(\varepsilon) \int_{T+\bar{\tau}}^{t} \sum_{j=1}^{n} f_{j}^{2}\left(x_{j}(\xi)\right) d \xi \leq V\left(x_{T+\bar{\tau}}\right),
$$

which implies that

$$
\sum_{j=1}^{n} \int_{0}^{+\infty} f_{j}^{2}\left(x_{j}(\xi)\right) d \xi<+\infty
$$

Moreover, from Lemma 2.1 and $\left(\mathrm{H}_{2}\right)-\left(\mathrm{H}_{3}\right)$ we see that $f_{j}^{2}\left(x_{j}(t)\right), j=1,2, \ldots, n$, are also uniformly continuous on $R_{+}$. Hence, Lemma 2.3 implies that

$$
\lim _{t \rightarrow+\infty}\left|f_{j}\left(x_{j}(t)\right)\right|=0, \quad j=1,2, \ldots, n
$$

Again from Lemma 2.1 and $\left(\mathrm{H}_{3}\right)$, we have

$$
\lim _{t \rightarrow+\infty} x_{j}(t)=0, \quad j=1,2, \ldots, n,
$$

that is,

$$
\lim _{t \rightarrow+\infty} u_{j}(t)=u_{j}^{*}, \quad j=1,2, \ldots, n,
$$

which shows that the equilibrium $\left(u_{1}^{*}, u_{2}^{*}, \ldots, u_{n}^{*}\right)$ of $(2.1)$ is globally attractive.

Furthermore, note $\left(\mathrm{H}_{2}\right),\left(\mathrm{H}_{3}\right)$, and the following inequalities:

$$
p_{i}<g_{i}^{\prime}\left(u_{i}^{*}\right)<q_{i}, \quad i=1,2, \ldots, n .
$$

We see that $\left(\mathrm{H}_{5}\right)$ implies $\left(\mathrm{H}_{6}\right)$ of Theorem 3.4 below. Thus, the equilibrium $\left(u_{1}^{*}\right.$, $\left.u_{2}^{*}, \ldots, u_{n}^{*}\right)$ of $(2.1)$ is also locally asymptotically stable. This proves Theorem 3.1 . 
$\left(\mathrm{H}_{5}^{\prime}\right)$ There exist positive constants $\lambda_{i}, i=1,2, \ldots, n$, such that

$$
\begin{aligned}
\gamma_{i}=\left\{\lambda_{i}(\right. & \left.-\frac{\underline{D}_{i}}{q_{i}}+w_{i i}+w_{i i}^{\tau}\right)+\frac{1}{2} \sum_{j=1}^{n}\left[\left(\frac{\lambda_{i} q_{j} \bar{D}_{j}}{p_{j}}\left|w_{i j}^{\tau}\right| \tau_{i j}(t)+\frac{\lambda_{j} q_{i} \bar{D}_{i}}{p_{i}}\left|w_{j i}^{\tau}\right| \tau_{j i}(t)\right)\right] \\
+ & \frac{1}{2} \sum_{j=1}^{n}\left[\lambda_{i} q_{j} \tau_{i j}(t)\left|w_{i j}^{\tau}\right| \sum_{k=1}^{n}\left(\left|w_{j k}\right|+\left|w_{j k}^{\tau}\right|\right)\right. \\
& \left.+\sum_{k=1}^{n} \lambda_{k} q_{j} \tau_{k j}(t)\left|w_{k j}^{\tau}\right|\left(\left|w_{j k}\right|+\left|w_{j k}^{\tau}\right|\right)\right] \\
& \left.+\frac{1}{2} \sum_{\substack{j=1 \\
j \neq i}}^{n}\left(\lambda_{i}\left|w_{i j}+w_{i j}^{\tau}\right|+\lambda_{j}\left|w_{j i}+w_{j i}^{\tau}\right|\right)\right\}<0 .
\end{aligned}
$$

By the process of the proof of Theorem 3.1 (see Appendix A), we can easily obtain.

Corollary 3.2. If $w_{i j}^{\tau} \neq 0$, for some $i, j=1,2, \ldots, n$, and $\left(H_{1}\right)-\left(H_{4}\right)$ and $\left(H_{5}^{\prime}\right)$ are satisfied, then the equilibrium $\left(u_{1}^{*}, u_{2}^{*}, \ldots, u_{n}^{*}\right)$ of system (2.1) is globally asymptotically stable.

Remark 3.3. In $[7,8,12]$, the authors require that the time-varying delays satisfy $\tau_{i j}^{\prime}(t) \leq$ $R<1$. However, in our theorem, these delays are not necessarily continuous and differentiable. They only need to satisfy the condition $0 \leq \tau_{i j}(t) \leq \bar{\tau}$. Hence, our results are less restrictive and conservative than the known results $[7,8,12]$.

Theorem 3.4. If $w_{i j}^{\tau} \neq 0$, for some $i, j=1,2, \ldots, n$, and $\left(H_{1}\right)-\left(H_{4}\right)$ and the following assumption $\left(H_{6}\right)$ are satisfied, there exist positive constants $\lambda_{i}, i=1,2, \ldots, n$, such that the following matrix:

$$
R^{*}=\left(\begin{array}{ccc}
\eta_{1}^{*} & r_{12} & r_{13} \cdots r_{1 n} \\
r_{21} & \eta_{2}^{*} & r_{23} \cdots r_{2 n} \\
\cdots & \cdots & \cdots \\
r_{n 1} & r_{n 2} & r_{n 3} \cdots \eta_{n}^{*}
\end{array}\right)
$$

is negative definite, where

$$
\begin{gathered}
\eta_{i}^{*}=\lambda_{i}\left(-\frac{\underline{D}_{i}}{g_{i}^{\prime}\left(u_{i}^{*}\right)}+w_{i i}+w_{i i}^{\tau}\right)+\frac{1}{2} \sum_{j=1}^{n}\left[\left(\lambda_{i} \bar{D}_{j}\left|w_{i j}^{\tau}\right| \tau_{i j}(t)+\lambda_{j} \bar{D}_{i}\left|w_{j i}^{\tau}\right| \tau_{j i}(t)\right)\right] \\
+\frac{1}{2} \sum_{j=1}^{n}\left[\lambda_{i} g_{j}^{\prime}\left(u_{j}^{*}\right) \tau_{i j}(t)\left|w_{i j}^{\tau}\right| \sum_{k=1}^{n}\left(\left|w_{j k}\right|+\left|w_{j k}^{\tau}\right|\right)\right. \\
\left.+\sum_{k=1}^{n} \lambda_{k} g_{j}^{\prime}\left(u_{j}^{*}\right) \tau_{k j}(t)\left|w_{k j}^{\tau}\right|\left(\left|w_{j k}\right|+\left|w_{j k}^{\tau}\right|\right)\right], \\
r_{i j}=\frac{1}{2}\left\{\lambda_{i}\left(w_{i j}+w_{i j}^{\tau}\right)+\lambda_{j}\left(w_{j i}+w_{j i}^{\tau}\right)\right\}, \quad i \neq j .
\end{gathered}
$$


Then, the equilibrium $\left(u_{1}^{*}, u_{2}^{*}, \ldots, u_{n}^{*}\right)$ of $(2.1)$ is locally asymptotically stable.

Proof. The linearized system of (2.1) at the equilibrium is given as

$$
\begin{aligned}
\dot{u}_{j}(t)= & -d_{i}\left(u_{i}(t)\right)+\sum_{j=1}^{n} w_{i j} g_{j}^{\prime}\left(u_{j}^{*}\right) u_{j}(t) \\
& +\sum_{j=1}^{n} w_{i j}^{\tau} g_{j}^{\prime}\left(u_{j}^{*}\right) u_{j}\left(t-\tau_{i j}(t)\right) \equiv G_{i}(\cdot), \quad i=1,2, \ldots, n,
\end{aligned}
$$

for $t \geq 0$. Therefore, for $t \geq \tau$, (3.16) can be further written as

$$
\begin{aligned}
\dot{u}_{i}(t)= & {\left[-d_{i}\left(u_{i}(t)\right)+\left(w_{i i}+w_{i i}^{\tau}\right) g_{i}^{\prime}\left(u_{i}^{*}\right)+\sum_{\substack{j=1 \\
j \neq i}}^{n}\left(w_{i j}+w_{i j}^{\tau}\right) g_{j}^{\prime}\left(u_{j}^{*}\right) u_{j}(t)\right] } \\
& +\sum_{j=1}^{n} w_{i j}^{\tau} g_{j}^{\prime}\left(u_{j}^{*}\right) \int_{t}^{t-\tau_{i j}(t)} G_{i}(\cdot) d \xi .
\end{aligned}
$$

By an argument similar to the one used in [4], we see that the stability of the trivial solution of (3.17) implies that of (3.16). Now, for (3.17), let us define a similar Lyapunov functional $\bar{V}=\bar{V}\left(u_{t}\right)$ as $V$ (see Appendix A):

$$
\bar{V}=\frac{1}{2} \sum_{i=1}^{n} \lambda_{i} g_{i}^{\prime}\left(u_{i}^{*}\right) u_{i}^{2}(t)+\bar{V}_{2},
$$

where the functional $\bar{V}_{2}=\bar{V}_{2}\left(u_{t}\right)$ is the same as $V_{2}$ but with setting

$$
p_{i \varepsilon}=q_{i \varepsilon}=g_{j}^{\prime}\left(u_{j}^{*}\right), \quad j=1,2, \ldots, n .
$$

Using the same type of computation as done in (3.6), we can show that

$$
\sum_{j=1}^{n} \int_{0}^{+\infty} u_{j}^{2}(t)<+\infty
$$

under $\left(\mathrm{H}_{1}\right)-\left(\mathrm{H}_{4}\right)$ and $\left(\mathrm{H}_{6}\right)$. Therefore, $u_{j}, j=1,2, \ldots, n$, are bounded on $\mathbb{R}_{+}$, and hence, are also uniformly continuous on $\mathbb{R}_{+}$. Again by Lemma 2.3 we have $\lim _{t \rightarrow+\infty} x_{j}(t)=0$, $j=1,2, \ldots, n$, which implies that the trivial solution of $(3.17)$ is asymptotically stable. This shows that $\left(u_{1}^{*}, u_{2}^{*}, \ldots, u_{n}^{*}\right)$ of $(2.1)$ is locally asymptotically stable. This proves Theorem 3.4 .

Similar to the process of proof for Theorem 3.1, the following corollary is immediate. Corollary 3.5. If $w_{i j}^{\tau} \neq 0$, for some $i, j=1,2, \ldots, n$, and $\left(H_{1}\right)-\left(H_{4}\right)$ and the following assumption $\left(H_{6}^{\prime}\right)$ are satisfied: 
$\left(\mathrm{H}_{6}^{\prime}\right)$ there exist positive constants $\lambda_{i}, i=1,2, \ldots, n$, such that

$$
\begin{aligned}
\gamma_{i}^{*}=\{ & \lambda_{i}\left(-\frac{\underline{D}_{j}}{g_{j}^{\prime}\left(u_{j}^{*}\right)}+w_{i i}+w_{i i}^{\tau}\right)+\frac{1}{2} \sum_{j=1}^{n}\left[\left(\lambda_{i} \bar{D}_{j}\left|w_{i j}^{\tau}\right| \tau_{i j}(t)+\lambda_{j} \bar{D}_{i}\left|w_{j i}^{\tau}\right| \tau_{j i}(t)\right)\right] \\
& +\sum_{j=1}^{n} \frac{g_{j}^{\prime}\left(u_{j}^{*}\right)}{2}\left[\lambda_{i} \tau_{i j}(t)\left|w_{i j}^{\tau}\right| \sum_{k=1}^{n}\left(\left|w_{j k}\right|+\left|w_{j k}^{\tau}\right|\right)\right. \\
& \left.+\sum_{k=1}^{n} \lambda_{k} \tau_{k j}(t)\left|w_{k j}^{\tau}\right|\left(\left|w_{j k}\right|+\left|w_{j k}^{\tau}\right|\right)\right] \\
& \left.+\frac{1}{2} \sum_{\substack{j=1 \\
j \neq i}}^{n}\left(\lambda_{i}\left|w_{i j}+w_{i j}^{\tau}\right|+\lambda_{j}\left|w_{j i}+w_{j i}^{\tau}\right|\right)\right\}<0
\end{aligned}
$$

then, the equilibrium $\left(u_{1}^{*}, u_{2}^{*}, \ldots, u_{n}^{*}\right)$ of $(2.1)$ is locally asymptotically stable.

If $d_{i}\left(x_{i}\right)=d_{i} x_{i}, d_{i}>0, \tau_{i j}(t)=\tau_{i j}$ (constant) in system (2.1), then system (2.1) is reduced to the following Hopfield-type neural networks with constant delays:

$$
\dot{u}_{i}(t)=-d_{i} u_{i}(t)+\sum_{j=1}^{n} w_{i j} g_{j}\left(u_{j}(t)\right)+\sum_{j=1}^{n} w_{i j}^{\tau} g_{j}\left(u_{j}\left(t-\tau_{i j}\right)\right)+I_{i}, \quad i=1,2, \ldots, n,
$$

where $u_{i}(t)$ corresponds to the membrane potential of the units $i$ at time $t ; g_{j}(\cdot)$ denotes a measure of response of activation to its incoming potentials; $w_{i j}$ and $w_{i j}^{\tau}$ denote the synaptic connection weights of unit $j$ to unit $i$; $\tau_{i j}$ corresponds the transmission delay along the axon of unit $j$ to unit $i$; the constant $I_{i}$ corresponds to the external bias of input from outside to unit $i$; and the coefficient $d_{i}$ is the rate with which unit $i$ self-regulates or resets its potential when isolated form other units and inputs.

Similar to the approach adopted in Theorem 3.1, we have the following result for system (3.22).

Theorem 3.6. If $w_{i j}^{\tau} \neq 0$, for some $i, j=1,2, \ldots, n$, and $\left(\mathrm{H}_{2}\right)-\left(\mathrm{H}_{3}\right)$ hold and there exist positive constants $\lambda_{i}, i=1,2, \ldots, n$, such that the following matrix:

$$
R=\left(\begin{array}{ccc}
\delta_{1} & r_{12} & r_{13} \cdots r_{1 n} \\
r_{21} & \delta_{2} & r_{23} \cdots r_{2 n} \\
\cdots & \cdots & \cdots \\
r_{n 1} & r_{n 2} & r_{n 3} \cdots \delta_{n}
\end{array}\right)
$$


is negative definite, that is,

$$
(-1)^{i}\left(\begin{array}{ccc}
\delta_{1} & r_{12} & r_{13} \cdots r_{1 n} \\
r_{21} & \delta_{2} & r_{23} \cdots r_{2 n} \\
\cdots & \cdots & \cdots \\
r_{n 1} & r_{n 2} & r_{n 3} \cdots \delta_{n}
\end{array}\right)>0, \quad i=1,2, \ldots, n
$$

where

$$
\begin{gathered}
\delta_{i}=\lambda_{i}\left(-\frac{d_{i}}{q_{i}}+w_{i i}+w_{i i}^{\tau}\right)+\frac{1}{2} \sum_{j=1}^{n}\left[\left(\frac{\lambda_{i} q_{j} d_{j}}{p_{j}}\left|w_{i j}^{\tau}\right| \tau_{i j}+\frac{\lambda_{j} q_{i} d_{i}}{p_{i}}\left|w_{j i}^{\tau}\right| \tau_{j i}\right)\right] \\
+\frac{1}{2} \sum_{j=1}^{n}\left[\lambda_{i} q_{j} \tau_{i j}\left|w_{i j}^{\tau}\right| \sum_{k=1}^{n}\left(\left|w_{j k}\right|+\left|w_{j k}^{\tau}\right|\right)+\sum_{k=1}^{n} \lambda_{k} q_{j} \tau_{k j}\left|w_{k j}^{\tau}\right|\left(\left|w_{j k}\right|+\left|w_{j k}^{\tau}\right|\right)\right], \\
r_{i j}=\frac{1}{2}\left\{\lambda_{i}\left(w_{i j}+w_{i j}^{\tau}\right)+\lambda_{j}\left(w_{j i}+w_{j i}^{\tau}\right)\right\}, \quad i \neq j,
\end{gathered}
$$

then, the equilibrium $\left(u_{1}^{*}, u_{2}^{*}, \ldots, u_{n}^{*}\right)$ of $(3.22)$ is unique and globally asymptotically stable.

Similar to the above Corollary 3.2, we have.

Corollary 3.7. If $w_{i j}^{\tau} \neq 0$, for some $i, j=1,2, \ldots, n,\left(H_{2}\right)-\left(H_{3}\right)$ are satisfied, and there exist positive constants $\lambda_{i}, i=1,2, \ldots, n$, such that

$$
\begin{aligned}
\rho_{i}=\{ & \lambda_{i}\left(-\frac{d_{i}}{q_{i}}+w_{i i}+w_{i i}^{\tau}\right)+\frac{1}{2} \sum_{j=1}^{n}\left[\left(\frac{\lambda_{i} q_{j} d_{j}}{p_{j}}\left|w_{i j}^{\tau}\right| \tau_{i j}+\frac{\lambda_{j} q_{i} \bar{D}_{i}}{p_{i}}\left|w_{j i}^{\tau}\right| \tau_{j i}\right)\right] \\
& +\frac{1}{2} \sum_{j=1}^{n}\left[\lambda_{i} q_{j} \tau_{i j}\left|w_{i j}^{\tau}\right| \sum_{k=1}^{n}\left(\left|w_{j k}\right|+\left|w_{j k}^{\tau}\right|\right)+\sum_{k=1}^{n} \lambda_{k} q_{j} \tau_{k j}\left|w_{k j}^{\tau}\right|\left(\left|w_{j k}\right|+\left|w_{j k}^{\tau}\right|\right)\right] \\
& \left.+\frac{1}{2} \sum_{j=1}^{n}\left(\lambda_{i}\left|w_{i j}+w_{i j}^{\tau}\right|+\lambda_{j}\left|w_{j i}+w_{j i}^{\tau}\right|\right)\right\}<0,
\end{aligned}
$$


then the equilibrium $\left(u_{1}^{*}, u_{2}^{*}, \ldots, u_{n}^{*}\right)$ of system (3.22) is unique and globally asymptotically stable.

Similar to the above Theorem 3.4, we have the following for system (3.22).

Theorem 3.8. If $w_{i j}^{\tau} \neq 0$, for some $i, j=1,2, \ldots, n,\left(H_{2}\right)-\left(H_{3}\right)$ are satisfied, and there exist positive constants $\lambda_{i}, i=1,2, \ldots, n$, such that the following matrix:

$$
R=\left(\begin{array}{ccc}
\delta_{1}^{*} & r_{12} & r_{13} \cdots r_{1 n} \\
r_{21} & \delta_{2}^{*} & r_{23} \cdots r_{2 n} \\
\cdots & \cdots & \cdots \\
r_{n 1} & r_{n 2} & r_{n 3} \cdots \delta_{n}^{*}
\end{array}\right)
$$

is negative definite, that is,

$$
(-1)^{i}\left(\begin{array}{ccc}
\delta_{1}^{*} & r_{12} & r_{13} \cdots r_{1 n} \\
r_{21} & \delta_{2}^{*} & r_{23} \cdots r_{2 n} \\
\cdots & \cdots & \cdots \\
r_{n 1} & r_{n 2} & r_{n 3} \cdots \delta_{n}^{*}
\end{array}\right)>0, \quad i=1,2, \ldots, n
$$

where

$$
\begin{gathered}
\delta_{i}^{*}=\lambda_{i}\left(-\frac{d_{j}}{g_{j}^{\prime}\left(u_{j}^{*}\right)}+w_{i i}+w_{i i}^{\tau}\right)+\frac{1}{2} \sum_{j=1}^{n}\left[\left(\lambda_{i} d_{j}\left|w_{i j}^{\tau}\right| \tau_{i j}+\lambda_{j} d_{i}\left|w_{j i}^{\tau}\right| \tau_{j i}\right)\right] \\
+\frac{1}{2} \sum_{j=1}^{n}\left[\lambda_{i} g_{j}^{\prime}\left(u_{j}^{*}\right) \tau_{i j}\left|w_{i j}^{\tau}\right| \sum_{k=1}^{n}\left(\left|w_{j k}\right|+\left|w_{j k}^{\tau}\right|\right)\right. \\
\left.+\sum_{k=1}^{n} \lambda_{k} g_{j}^{\prime}\left(u_{j}^{*}\right) \tau_{k j}\left|w_{k j}^{\tau}\right|\left(\left|w_{j k}\right|+\left|w_{j k}^{\tau}\right|\right)\right], \\
r_{i j}=\frac{1}{2}\left\{\lambda_{i}\left(w_{i j}+w_{i j}^{\tau}\right)+\lambda_{j}\left(w_{j i}+w_{j i}^{\tau}\right)\right\}, \quad i \neq j,
\end{gathered}
$$

then, the equilibrium $\left(u_{1}^{*}, u_{2}^{*}, \ldots, u_{n}^{*}\right)$ of $(2.1)$ is locally asymptotically stable.

Similar to Corollary 3.5, for system (3.22), we have the following. 


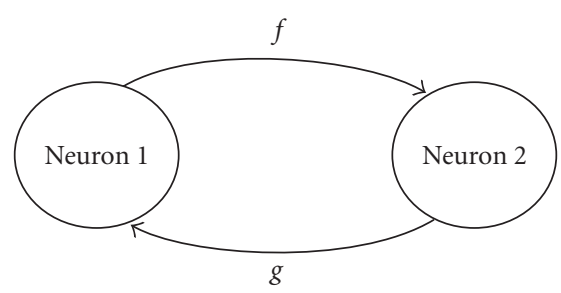

Figure 4.1. The model of two-neuron system.

Corollary 3.9. If $w_{i j}^{\tau} \neq 0$, for some $i, j=1,2, \ldots, n,\left(\mathrm{H}_{2}\right)-\left(\mathrm{H}_{3}\right)$ are satisfied, and there exist positive constants $\lambda_{i}, i=1,2, \ldots, n$, such that

$$
\begin{aligned}
\rho_{i}^{*}=\{ & \lambda_{i}\left(-\frac{d_{j}}{g_{j}^{\prime}\left(u_{j}^{*}\right)}+w_{i i}+w_{i i}^{\tau}\right)+\frac{1}{2} \sum_{j=1}^{n}\left[\left(\lambda_{i} d_{j}\left|w_{i j}^{\tau}\right| \tau_{i j}+\lambda_{j} d_{i}\left|w_{j i}^{\tau}\right| \tau_{j i}\right)\right] \\
& +\sum_{j=1}^{n} \frac{g_{j}^{\prime}\left(u_{j}^{*}\right)}{2}\left[\lambda_{i} \tau_{i j}\left|w_{i j}^{\tau}\right| \sum_{k=1}^{n}\left(\left|w_{j k}\right|+\left|w_{j k}^{\tau}\right|\right)+\sum_{k=1}^{n} \lambda_{k} \tau_{k j}\left|w_{k j}^{\tau}\right|\left(\left|w_{j k}\right|+\left|w_{j k}^{\tau}\right|\right)\right] \\
& \left.+\frac{1}{2} \sum_{j=1}^{n}\left(\lambda_{i}\left|w_{i j}+w_{i j}^{\tau}\right|+\lambda_{j}\left|w_{j i}+w_{j i}^{\tau}\right|\right)\right\}<0,
\end{aligned}
$$

then, the equilibrium $\left(u_{1}^{*}, u_{2}^{*}, \ldots, u_{n}^{*}\right)$ of (3.22) is locally asymptotically stable.

\section{Application to two-neuron system with delays}

In this section, the following two-neuron system with different time delays which is capable of firing or responding continuously with time is considered. Particularly, the firing is modulated by the difference between its current status and a weighted average of the firing history [6]:

$$
\dot{x}_{1}(t)=-x_{1}(t)+a_{1} g\left[x_{2}(t)-b_{2} x_{2}(t-\tau)\right], \quad \dot{x}_{2}(t)=-x_{2}(t)+a_{2} f\left[x_{1}(t)-b_{1} x_{1}(t-\sigma)\right],
$$

where "•" denotes the derivative, with $t, a_{1}, a_{2}, b_{1}$, and $b_{2}$ are arbitrary real numbers. In (4.1), $x_{1}$ and $x_{2}$ denote the mean soma potential of the neuron, while $a_{1}$ and $a_{2}$ correspond to the range of the continuous variables $x_{1}$ and $x_{2}$, respectively. $b_{1}$ and $b_{2}$ denote the measure of the inhibitory influence of the past history. The terms $x_{1}$ and $x_{2}$ in the argument of the $f$ and $g$ function denote local feedbacks. In biological literature, such feedback is known as reverberation, while in the literature on artificial neural networks, it is known as an excitation from other neurons (see Figure 4.1). 
The initial condition for (2.1) is given as follows:

$$
x_{1}(s)=\Phi(s), \quad x_{2}(s)=\Psi(s), \quad-\Delta \leq s \leq 0,
$$

where $\Delta \equiv \max \{\tau, \sigma\}, \Phi(s)$ and $\Psi(s)$ are continuous on $[-\Delta, 0]$.

By using the following transformation:

$$
y_{1}(t)=x_{1}(t)-b_{1} x_{1}(t-\sigma), \quad y_{2}(t)=x_{2}(t)-b_{2} x_{2}(t-\tau)
$$

we can transform system (4.1) to

$$
\begin{aligned}
& \dot{y}_{1}(t)=-y_{1}(t)+a_{1} g\left(y_{2}(t)\right)-a_{1} b_{1} g\left(y_{2}(t-\sigma)\right), \\
& \dot{y}_{2}(t)=-y_{2}(t)+a_{2} f\left(y_{1}(t)\right)-a_{2} b_{2} f\left(y_{1}(t-\tau)\right)
\end{aligned}
$$

for $t \geq 0$, where $a_{1}, a_{2}, b_{1}$, and $b_{2}$ are real constants. The delays $\tau$ and $\sigma$ are nonnegative constants. The function $f$ and $g$ are continuously differentiable on $R=(-\infty,+\infty)$ and such that $f(0)=0, g(0)=0$.

For (4.1) or (4.4), we assume that the following conditions are satisfied.

$\left(\mathrm{A}_{1}\right) f$ and $g$ are bounded on $R$, that is, there exist positive constants $Q$ and $L$ such that, for any $w \in R$,

$$
|f(w)| \leq Q, \quad|g(w)| \leq L
$$

$\left(\mathrm{A}_{2}\right)$ For any $w \in R, f^{\prime}(w)>0, g^{\prime}(w)>0$.

Remark 4.1. In [6], Liao et al. derived $f(\cdot)=g(\cdot)=\tanh (\cdot)$. However, here we only require that $f$ and $g$ satisfy the conditions $\left(\mathrm{A}_{1}\right)$ and $\left(\mathrm{A}_{2}\right)$. Moreover, our model (4.1) and the obtained results are more general than those of [6].

It is easy to show that under $\left(A_{1}\right)-\left(A_{2}\right)$, the solution of (4.1) or (4.4) satisfying the initial condition (4.2) exists on $R_{+} \equiv[0,+\infty)$ (see, e.g., [4]). In fact, from Lemma 2.1 above, it is clear that the solution of (4.4) is also unique.

It is also easy to show that (4.4) has always an equilibrium $\left(y_{1}^{*}, y_{2}^{*}\right)$, that is, there exist $y_{1}^{*}$ and $y_{2}^{*}$ such that

$$
y_{1}^{*}-a_{1} g\left(y_{2}^{*}\right)+a_{1} b_{1} g\left(y_{2}^{*}\right)=0, \quad y_{2}^{*}-a_{2} f\left(y_{1}^{*}\right)+a_{2} b_{2} f\left(y_{1}^{*}\right)=0 .
$$

In fact, we consider the map $P=\left(P_{1}, P_{2}\right)$ on the compact convex set $\Omega$, where

$$
\begin{gathered}
P_{1}\left(y_{1}, y_{2}\right)=a_{1} g\left(y_{2}\right)-a_{1} b_{1} g\left(y_{2}\right), \quad P_{2}\left(y_{1}, y_{2}\right)=a_{2} f\left(y_{1}\right)-a_{2} b_{2} f\left(y_{1}\right), \\
\Omega=\left\{\left(y_{1}, y_{2}\right)|| y_{1}\left|\leq M_{0},\right| y_{2} \mid \leq N_{0}\right\}, \\
M_{0}=\left|a_{1}\right|\left(1+\left|b_{1}\right|\right) L, \quad N_{0}=\left|a_{2}\right|\left(1+\left|b_{2}\right|\right) Q .
\end{gathered}
$$


It follows from $\left(\mathrm{A}_{1}\right)$ that $P$ is a continuous map which maps $\Omega$ into itself. Thus, it follows from Brouwer's fixed point theorem that $P$ has at least one fixed point $\left(y_{1}^{*}, y_{2}^{*}\right)$ in $\Omega$, that is,

$$
\left(y_{1}^{*}, y_{2}^{*}\right)=P\left(y_{1}^{*}, y_{2}^{*}\right) .
$$

This shows that $\left(y_{1}^{*}, y_{2}^{*}\right)$ satisfies (4.6).

In this section, we will consider the stability of the equilibrium $\left(y_{1}^{*}, y_{2}^{*}\right)$ of (4.4).

Let us first consider the case $a_{1} a_{2}\left(1-b_{1}\right)\left(1-b_{2}\right) \neq 1$. We further make the following assumption.

$\left(\mathrm{A}_{3}\right)$ There exist positive constants $d_{1}$ and $d_{2}$ such that

$$
\begin{gathered}
\kappa_{1}=-\frac{2 d_{1}}{l}+\left[d_{1}\left|a_{1} b_{1}\right| \frac{q}{p} \sigma+d_{2}\left|a_{2} b_{2}\right| \frac{l}{h} \tau\right]+2 d_{1}\left|a_{1} b_{1}\right|\left|a_{2}\right|\left(1+\left|b_{2}\right|\right) q \sigma<0, \\
\kappa_{2}=-\frac{2 d_{2}}{q}+\left[d_{2}\left|a_{2} b_{2}\right| \frac{l}{h} \tau+d_{1}\left|a_{1} b_{1}\right| \frac{q}{p} \sigma\right]+2 d_{2}\left|a_{2} b_{2}\right|\left|a_{1}\right|\left(1+\left|b_{1}\right|\right) l \tau<0, \\
\kappa_{1} \kappa_{2}>\left[d_{1} a_{1}\left(1-b_{1}\right)+d_{2} a_{2}\left(1-b_{2}\right)\right]^{2} .
\end{gathered}
$$

Hence, the equilibrium $\left(y_{1}^{*}, y_{2}^{*}\right)$ of $(4.4)$ is also unique.

Similar to the above approach (see Appendix B), we can easily obtain the following.

THeOREM 4.2. If $a_{1} a_{2}\left(1-b_{1}\right)\left(1-b_{2}\right) \neq 1$ and $\left(A_{1}\right)-\left(A_{3}\right)$ are satisfied, then the equilibrium $\left(y_{1}^{*}, y_{2}^{*}\right)$ of (4.4) is globally asymptotically stable.

THeORem 4.3. If $a_{1} a_{2}\left(1-b_{1}\right)\left(1-b_{2}\right) \neq 1$ and $\left(A_{1}\right)-\left(A_{2}\right)$ and the following assumption $\left(A_{4}\right)$ are satisfied:

$\left(\mathrm{A}_{4}\right)$ there exist positive constants $d_{1}$ and $d_{2}$ such that

$$
\begin{gathered}
\kappa_{1}^{*}=-\frac{2 d_{1}}{f^{\prime}\left(y_{1}^{*}\right)}+\left[d_{1}\left|a_{1} b_{1}\right| \sigma+d_{2}\left|a_{2} b_{2}\right| \tau\right]+2 d_{1}\left|a_{1} b_{1}\right|\left|a_{2}\right|\left(1+\left|b_{2}\right|\right) g^{\prime}\left(y_{2}^{*}\right) \sigma<0, \\
\kappa_{2}^{*}=-\frac{2 d_{2}}{g^{\prime}\left(y_{2}^{*}\right)}+\left[d_{2}\left|a_{2} b_{2}\right| \tau+d_{1}\left|a_{1} b_{1}\right| \sigma\right]+2 d_{2}\left|a_{2} b_{2}\right|\left|a_{1}\right|\left(1+\left|b_{1}\right|\right) f^{\prime}\left(y_{1}^{*}\right) \tau<0, \\
\kappa_{1}^{*} \kappa_{2}^{*}>\left[d_{1} a_{1}\left(1-b_{1}\right)+d_{2} a_{2}\left(1-b_{2}\right)\right]^{2},
\end{gathered}
$$

then, the equilibrium $\left(y_{1}^{*}, y_{2}^{*}\right)$ of (4.4) is locally asymptotically stable.

In general, the delay-independent criteria are particularly restrictive for system parameters. Thus, it is reasonable to apply these criteria first. If they are found inappropriate, the delay-dependent criteria will then be applied. To illustrate the results presented in Theorems 4.2 and 4.3, some simple examples are given and a comparison of the results is given in Table 4.1 .

From Table 4.1, we can easily find that the delay-independent conditions given in [6] are not applied and satisfied. This illustrates that the delay-independent criteria are more conservative and restrictive than the delay-dependent criteria. Numerical simulation results are shown in Figures 4.2 and 4.3. 
Table 4.1. A comparison of the delay-dependent stability criteria when $\sigma=0.5 \tau$.

\begin{tabular}{ccc}
\hline System Parameters & Results given by [6] & Our results \\
\hline $\begin{array}{c}a_{1}=0.8, a_{2}=1 \\
b_{1}=3, b_{2}=-3\end{array}$ & $\tau<0.1111$ & $\tau<0.1449$ \\
\hline$a_{1}=2, a_{2}=0.42$ & $\tau<0.4535$ & \\
$b_{1}=0.5, b_{2}=-2$ & & $\tau<0.6623$ \\
\hline$a_{1}=0.2, a_{2}=0.5$ & $\tau<1.0667$ & $\tau<1.4285$ \\
$b_{1}=3.5, b_{2}=2$ & & $\tau<1.4706$ \\
\hline$a_{1}=2, a_{2}=1$ & $\tau<0.9804$ & \\
$b_{1}=0.4, b_{2}=0.2$ & & $\tau<4.7618$ \\
\hline$a_{1}=1.75, a_{2}=0.5$ & $\tau<2.2409$ & \\
$b_{1}=0.2, b_{2}=-0.4$ & & $\tau<8.7912$ \\
\hline$a_{1}=0.35, a_{2}=2.5$ & & \\
$b_{1}=0.2, b_{2}=0.1$ & & \\
\hline
\end{tabular}

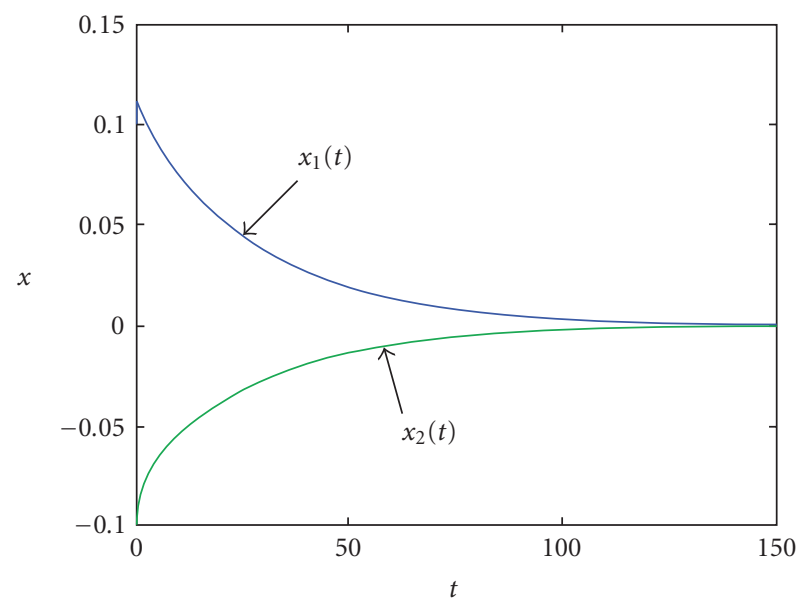

Figure 4.2. Time response of state variable for system (4.1) under $a_{1}=1.75, a_{2}=0.5, b_{1}=0.2, b_{2}=$ $-0.4, \tau=2.24, \sigma=0.5 \tau$.

For system (4.1) under $a_{1}=1.75, a_{2}=0.5, b_{1}=0.2, b_{2}=-0.4, \sigma=0.5 \tau$, numerical simulations have also been performed (see Figures 4.2-4.5). It is suggested that the trivial solution of (4.1) still remains globally asymptotically stable for $\tau<17$ (see Figures 4.2 and 4.3). This shows that our results are actually rather restrictive and there is much room for 


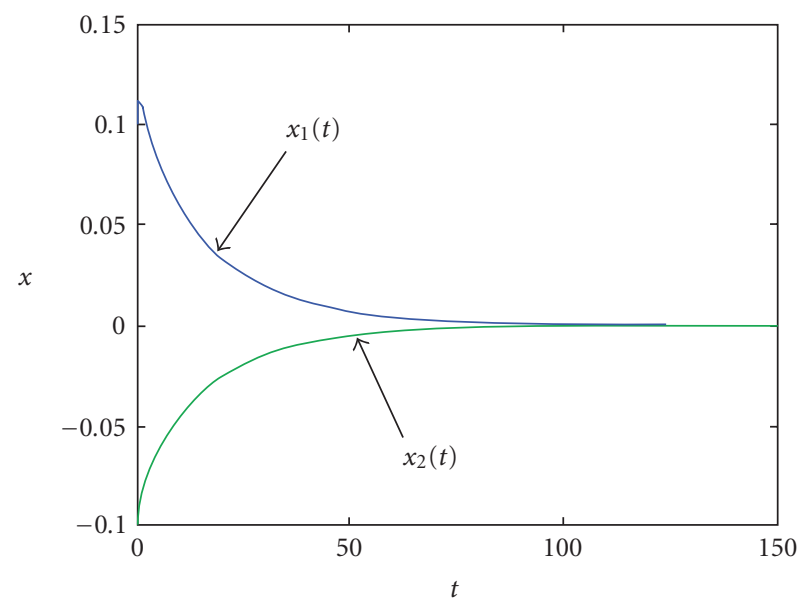

Figure 4.3. Time response of state variable for system (4.1) under $a_{1}=1.75, a_{2}=0.5, b_{1}=0.2, b_{2}=$ $-0.4, \tau=4.761, \sigma=0.5 \tau$.

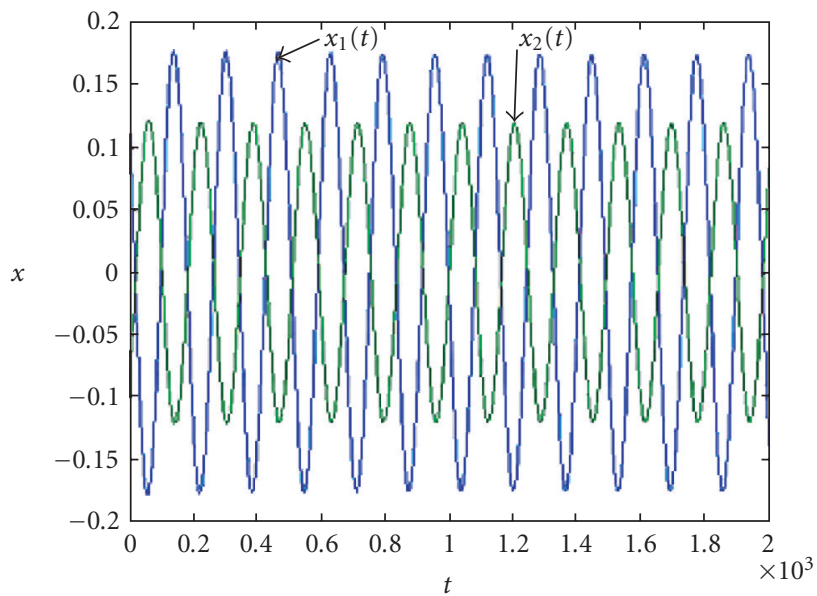

Figure 4.4. Time response of state variable $x_{1}(\mathrm{t})$ for system (4.1) under $a_{1}=1.75, a_{2}=0.5, b_{1}=0.2$, $b_{2}=-0.4, \tau=18, \sigma=0.5 \tau$.

improvement. Numerical simulations also show that for $\tau=18$, almost all solutions of (2.1) are oscillatory and ultimately tend to some periodic solution (see Figures 4.4 and 4.5). Hence, the problem of whether the delay super-bound is optimal will be studied in a forthcoming paper.

\section{Conclusions}

In this paper, we have analyzed a system composed of multiple neurons with time-varying delays in detail. We first obtained the global asymptotically stable criteria dependent on delays for the equilibrium by employing the approach of Lyapunov functional. Our results are delay dependent. Then, we also derived the delay-dependent criteria for local 


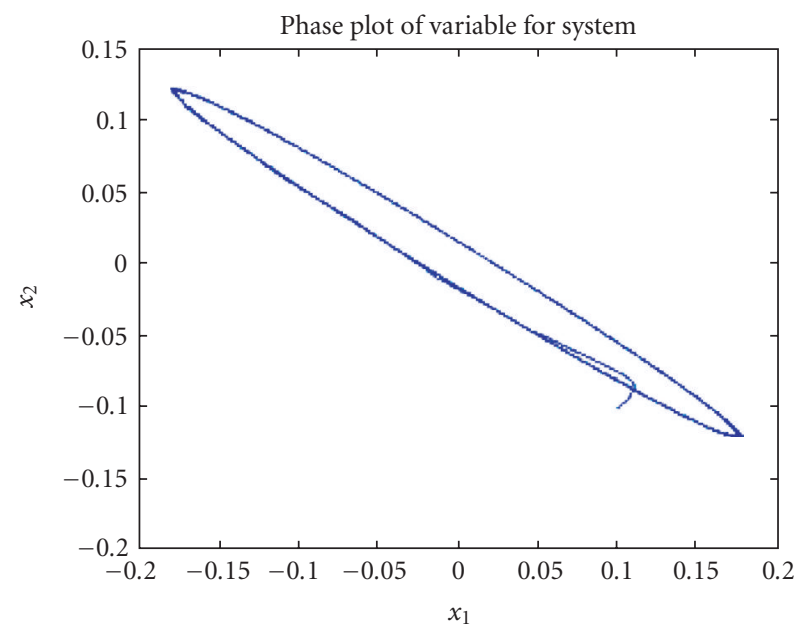

Figure 4.5. Time response of state variables $x_{1}(t)$ and $x_{2}(t)$ for system (4.1) under $a_{1}=1.75, a_{2}=0.5$, $b_{1}=0.2, b_{2}=-0.4, \tau=18, \sigma=0.5 \tau$.

asymptotic stability. Hence, our work complements and generalizes that is reported in $[7,8,11-13]$. In the meantime, we note also that, if the neural system starts with a stable equilibrium, but then becomes unstable due to delays, it will likely be destabilized by means of a Hopf bifurcation leading to periodic solutions with small amplitudes $[14,15,18]$. The analysis of such a bifurcation to find out its bifurcation direction and stability of the periodic solutions is very complicated and lengthy. It is worth studying whether there are other dynamical behaviors, such as codimension-two bifurcations, periodic-doubling bifurcations, phase-locking and quasiperiodic dynamics, and so forth, These works will be studied in the near future.

\section{Appendices}

\section{A. Stability proof}

We construct the following Lyapunov function:

$$
V_{1}=\sum_{j=1}^{n} \lambda_{i} \int_{0}^{x_{i}(t)} f_{i}(\xi) d \xi
$$

then its upper right Dini-derivative is

$$
\begin{aligned}
\left.D^{+} V_{1}\right|_{(3.5)}= & \sum_{i=1}^{n} \lambda_{i} f_{i}\left(x_{i}(t)\right)\left[-h_{i}\left(x_{i}(t)\right)+w_{i i} f_{i}\left(x_{i}(t)\right)+w_{i i}^{\tau} f_{i}\left(x_{i}(t)\right)\right] \\
& +\sum_{i=1}^{n} \lambda_{i} f_{i}\left(x_{i}(t)\right) \alpha_{i}+\sum_{\substack{i=1 \\
j}}^{n} \sum_{\substack{j=1 \\
j \neq i}}^{n} \lambda_{i}\left(w_{i j}+w_{i j}^{\tau}\right) f_{i}\left(x_{i}(t)\right) f_{j}\left(x_{j}(t)\right),
\end{aligned}
$$


where

$$
\alpha_{i}=\sum_{j=1}^{n} w_{i j}^{\tau} \int_{t}^{t-\tau_{i j}(t)} f_{j}^{\prime}\left(x_{j}(\xi)\right) x_{j}^{\prime}(\xi) d \xi
$$

We note that

$$
p_{i \varepsilon} \equiv \min _{-\left(N_{i}+\varepsilon\right) \leq w \leq N_{i}+\varepsilon} f_{i}^{\prime}(w) \leq \max _{-\left(N_{i}+\varepsilon\right) \leq w \leq N_{i}+\varepsilon} f_{i}^{\prime}(w) \equiv q_{i \varepsilon} .
$$

Note that for sufficiently large $t$,

$$
\left|x_{i}(t)\right| \leq \frac{\left|f_{i}\left(x_{i}(t)\right)\right|}{p_{i \varepsilon}} .
$$

Then

$$
\begin{aligned}
& \left|f_{i}\left(x_{i}(t)\right) \alpha_{i}\right| \leq\left|f_{i}\left(x_{i}(t)\right)\right| \sum_{j=1}^{n}\left|w_{i j}^{\tau}\right| \int_{t-\tau_{i j}(t)}^{t}\left|f_{j}^{\prime}\left(x_{j}(\xi)\right)\right|\left|x_{j}^{\prime}(\xi)\right| d \xi \\
& \leq\left|f_{i}\left(x_{i}(t)\right)\right| \sum_{j=1}^{n}\left|w_{i j}^{\tau}\right| \\
& \times \int_{t-\tau_{i j}(t)}^{t} q_{j \varepsilon}\left(\left|h_{j}\left(x_{j}(\xi)\right)\right|+\sum_{k=1}^{n}\left|w_{j k}\right|\left|f_{k}\left(x_{k}(\xi)\right)\right|\right. \\
& \left.+\sum_{k=1}^{n}\left|w_{j k}^{\tau}\right|\left|f_{k}\left(x_{k}\left(\xi-\tau_{j k}(\xi)\right)\right)\right|\right) d \xi \\
& \leq\left|f_{i}\left(x_{i}(t)\right)\right| \sum_{j=1}^{n}\left|w_{i j}^{\tau}\right| \\
& \times \int_{t-\tau_{i j}(t)}^{t} q_{j \varepsilon}\left(\frac{\bar{D}_{j}}{p_{j \varepsilon}}\left|f_{j}\left(x_{j}(\xi)\right)\right|+\sum_{k=1}^{n}\left|w_{j k}\right|\left|f_{k}\left(x_{k}(\xi)\right)\right|\right. \\
& \left.+\sum_{k=1}^{n}\left|w_{j k}^{\tau}\right|\left|f_{k}\left(x_{k}\left(\xi-\tau_{j k}(\xi)\right)\right)\right|\right) d \xi \\
& \leq \frac{1}{2} \sum_{j=1}^{n}\left|w_{i j}^{\tau}\right| q_{j \varepsilon} \\
& \times \int_{t-\tau_{i j}(t)}^{t}\left\{\frac{\bar{D}_{j}}{p_{j \varepsilon}}\left[f_{i}^{2}\left(x_{i}(t)\right)+f_{j}^{2}\left(x_{j}(\xi)\right)\right]\right.
\end{aligned}
$$




$$
\begin{gathered}
+\sum_{k=1}^{n}\left|w_{j k}\right|\left[f_{i}^{2}\left(x_{i}(t)\right)+f_{k}^{2}\left(x_{k}(\xi)\right)\right] \\
\left.+\sum_{k=1}^{n}\left|w_{j k}^{\tau}\right|\left[f_{i}^{2}\left(x_{i}(t)\right)+f_{k}^{2}\left(x_{k}\left(\xi-\tau_{j k}(\xi)\right)\right)\right]\right\} d \xi \\
=\frac{1}{2} \sum_{j=1}^{n}\left|w_{i j}^{\tau}\right| q_{j \varepsilon} \tau_{i j}(t)\left[\frac{\bar{D}_{j}}{p_{j \varepsilon}}+\sum_{k=1}^{n}\left(\left|w_{j k}\right|+\left|w_{j k}^{\tau}\right|\right)\right] f_{i}^{2}\left(x_{i}(t)\right) \\
+\frac{1}{2} \sum_{j=1}^{n}\left|w_{i j}^{\tau}\right| \int_{t-\tau_{i j}(t)}^{t} q_{j \varepsilon}\left[\frac{\bar{D}_{j}}{p_{j \varepsilon}} f_{j}^{2}\left(x_{j}(\xi)\right)+\sum_{k=1}^{n}\left|w_{j k}\right| f_{k}^{2}\left(x_{k}(\xi)\right)\right. \\
\left.+\sum_{k=1}^{n}\left|w_{j k}^{\tau}\right| f_{k}^{2}\left(x_{k}\left(\xi-\tau_{j k}(\xi)\right)\right)\right] d \xi \\
=\sum_{j=1}^{n}\left|w_{i j}^{\tau}\right|\left(A_{i j \varepsilon} f_{i}^{2}\left(x_{i}(t)\right)+\int_{t-\tau_{i j}(t)}^{t} \mu_{j \varepsilon}(\xi) d \xi\right),
\end{gathered}
$$

where

$$
\begin{gathered}
A_{i j \varepsilon}=\frac{1}{2} q_{j \varepsilon} \tau_{i j}(t)\left[\frac{\bar{D}_{j}}{p_{j \varepsilon}}+\sum_{k=1}^{n}\left(\left|w_{j k}\right|+\left|w_{j k}^{\tau}\right|\right)\right], \\
\mu_{j \varepsilon}(\xi)=\frac{1}{2} q_{j \varepsilon}\left[\frac{\bar{D}_{j}}{p_{j \varepsilon}} f_{j}^{2}\left(x_{j}(\xi)\right)+\sum_{k=1}^{n}\left|w_{j k}\right| f_{k}^{2}\left(x_{k}(\xi)\right)+\sum_{k=1}^{n}\left|w_{j k}^{\tau}\right| f_{k}^{2}\left(x_{k}\left(\xi-\tau_{j k}(\xi)\right)\right)\right] .
\end{gathered}
$$

Furthermore, by $\left(\mathrm{H}_{1}\right)$, we have for $t \geq T+\Delta$,

$$
\begin{gathered}
f_{i}\left(x_{i}(t)\right)\left[-h_{i}\left(x_{i}(t)\right)+w_{i i} f_{i}\left(x_{i}(t)\right)+w_{i i}^{\tau} f_{i}\left(x_{i}(t)\right)\right] \\
\leq-\underline{D}_{i} x_{i}(t) f_{i}\left(x_{i}(t)\right)+\left(w_{i i}+w_{i i}^{\tau}\right) f_{i}^{2}\left(x_{i}(t)\right) \\
\leq\left[-\frac{D_{i}}{q_{i \varepsilon}}+\left(w_{i i}+w_{i i}^{\tau}\right)\right] f_{i}^{2}\left(x_{i}(t)\right) .
\end{gathered}
$$

Therefore,

$$
\begin{aligned}
\left.D^{+} V_{1}\right|_{(3.5)} \leq & \sum_{i=1}^{n} \lambda_{i}\left[-\frac{\underline{D}_{i}}{q_{i \varepsilon}}+\left(w_{i i}+w_{i i}^{\tau}\right)\right] f_{i}^{2}\left(x_{i}(t)\right) \\
& +\sum_{i=1}^{n} \sum_{j=1}^{n} \lambda_{i}\left|w_{i j}^{\tau}\right|\left(A_{i j \varepsilon} f_{i}^{2}\left(x_{i}(t)\right)+\int_{t-\tau_{i j}(t)}^{t} \mu_{j \varepsilon}(\xi) d \xi\right) \\
& +\sum_{i=1}^{n} \sum_{\substack{j=1 \\
j \neq i}}^{n} \lambda_{i}\left(w_{i j}+w_{i j}^{\tau}\right) f_{i}\left(x_{i}(t)\right) f_{j}\left(x_{j}(t)\right) .
\end{aligned}
$$


Let

$$
V_{2}=\sum_{i=1}^{n} \sum_{j=1}^{n} \lambda_{i}\left|w_{i j}^{\tau}\right|\left(\int_{t-\tau_{i j}(t)}^{t} \int_{\theta}^{t} \mu_{j \varepsilon}(\xi) d \xi d \theta+\frac{\tau_{i j}(t) q_{j \varepsilon}}{2} \sum_{k=1}^{n}\left|w_{j k}^{\tau}\right| \int_{t-\tau_{j k}(t)}^{t} f_{k}^{2}\left(x_{k}(\xi)\right) d \xi\right) .
$$

Its derivative is

$$
\begin{aligned}
\left.D^{+} V_{2}\right|_{(3.5)}= & \sum_{i=1}^{n} \sum_{j=1}^{n} \frac{\lambda_{i} q_{j \varepsilon}}{2}\left|w_{i j}^{\tau}\right| \tau_{i j}(t)\left(\frac{\bar{D}_{j}}{p_{j \varepsilon}} f_{j}^{2}\left(x_{j}(t)\right)+\sum_{k=1}^{n}\left(\left|w_{j k}\right|+\left|w_{j k}^{\tau}\right|\right) f_{k}^{2}\left(x_{k}(t)\right)\right) \\
& -\sum_{i=1}^{n} \sum_{j=1}^{n} \lambda_{i}\left|w_{i j}^{\tau}\right| \int_{t-\tau_{i j}(t)}^{t} \mu_{j \varepsilon}(\xi) d \xi .
\end{aligned}
$$

Hence,

$$
\begin{aligned}
D^{+} V= & D^{+} V_{1}+D^{+} V_{2} \\
\leq & \sum_{i=1}^{n} \lambda_{i}\left[-\frac{\underline{D}_{i}}{q_{i \varepsilon}}+\left(w_{i i}+w_{i i}^{\tau}\right)\right] f_{i}^{2}\left(x_{i}(t)\right)+\sum_{i=1}^{n} \sum_{j=1}^{n} \lambda_{i}\left|w_{i j}^{\tau}\right| A_{i j \varepsilon} f_{i}^{2}\left(x_{i}(t)\right) \\
& +\sum_{i=1}^{n} \sum_{j=1}^{n} \lambda_{i}\left(w_{i j}+w_{i j}^{\tau}\right) f_{i}\left(x_{i}(t)\right) f_{j}\left(x_{j}(t)\right) \\
& +\sum_{i=1}^{n} \sum_{j=1}^{n} \frac{\lambda_{i} q_{j \varepsilon}}{2}\left|w_{i j}^{\tau}\right| \tau_{i j}(t)\left(\frac{\bar{D}_{j}}{p_{j \varepsilon}} f_{j}^{2}\left(x_{j}(t)\right)+\sum_{k=1}^{n}\left(\left|w_{j k}\right|+\left|w_{j k}^{\tau}\right|\right) f_{k}^{2}\left(x_{k}(t)\right)\right) \\
\leq & \sum_{i=1}^{n}\left\{\lambda_{i}\left(-\frac{D_{i}}{q_{i \varepsilon}}+w_{i i}+w_{i i}^{\tau}+\sum_{j=1}^{n} A_{i j \varepsilon}\left|w_{i j}^{\tau}\right|+\sum_{j=1}^{n} \lambda_{j}\left|w_{j i}^{\tau}\right| \tau_{j i}(t) \frac{q_{i \varepsilon} \bar{D}_{i}}{2 p_{i \varepsilon}}\right)\right. \\
& \left.+\frac{1}{2} \sum_{j=1}^{n} \sum_{k=1}^{n} \lambda_{k} q_{j \varepsilon}\left|w_{k j}^{\tau}\right| \tau_{k j}(t)\left(\left|w_{j i}\right|+\left|w_{j i}^{\tau}\right|\right)\right\} f_{i}^{2}\left(x_{i}(t)\right) \\
& +\sum_{i=1}^{n} \sum_{j=1}^{n} \lambda_{i}\left(w_{i j}+w_{i j}^{\tau}\right) f_{i}\left(x_{i}(t)\right) f_{j}\left(x_{j}(t)\right)
\end{aligned}
$$




$$
\begin{aligned}
& =\sum_{i=1}^{n}\left\{\lambda _ { i } \left(-\frac{\underline{D}_{i}}{q_{i \varepsilon}}+w_{i i}+w_{i i}^{\tau}+\frac{1}{2} \sum_{j=1}^{n} q_{j \varepsilon}\left|w_{i j}^{\tau}\right| \tau_{i j}(t)\left(\frac{\bar{D}_{j}}{p_{j \varepsilon}}+\sum_{k=1}^{n}\left(\left|w_{j k}\right|+\left|w_{j k}^{\tau}\right|\right)\right)\right.\right. \\
& \left.\left.+\sum_{j=1}^{n} \lambda_{j}\left|w_{j i}^{\tau}\right| \tau_{j i}(t) \frac{q_{i \varepsilon} \bar{D}_{i}}{2 p_{i \varepsilon}}\right)+\frac{1}{2} \sum_{j=1}^{n} \sum_{k=1}^{n} \lambda_{k} q_{j \varepsilon}\left|w_{k j}^{\tau}\right| \tau_{k j}(t)\left(\left|w_{j i}\right|+\left|w_{j i}^{\tau}\right|\right)\right\} \\
& \times f_{i}^{2}\left(x_{i}(t)\right)+\sum_{i=1}^{n} \sum_{\substack{j=1 \\
j \neq i}}^{n} \lambda_{i}\left(w_{i j}+w_{i j}^{\tau}\right) f_{i}\left(x_{i}(t)\right) f_{j}\left(x_{j}(t)\right) \\
& =\sum_{i=1}^{n}\left\{\lambda_{i}\left(-\frac{\underline{D}_{i}}{q_{i \varepsilon}}+w_{i i}+w_{i i}^{\tau}\right)+\frac{1}{2} \sum_{j=1}^{n}\left[\frac{\lambda_{i} q_{j \varepsilon} \bar{D}_{j}}{p_{j \varepsilon}}\left|w_{i j}^{\tau}\right| \tau_{i j}(t)+\frac{\lambda_{j} q_{i \varepsilon} \bar{D}_{i}}{p_{i \varepsilon}}\left|w_{j i}^{\tau}\right| \tau_{j i}(t)\right]\right. \\
& +\frac{1}{2} \sum_{j=1}^{n}\left[\lambda_{i} q_{j \varepsilon} \tau_{i j}(t)\left|w_{i j}^{\tau}\right| \sum_{k=1}^{n}\left(\left|w_{j k}\right|+\left|w_{j k}^{\tau}\right|\right)\right. \\
& \left.\left.+\sum_{k=1}^{n} \lambda_{k} q_{j \varepsilon}\left|w_{k j}^{\tau}\right| \tau_{k j}(t)\left(\left|w_{j i}\right|+\left|w_{j i}^{\tau}\right|\right)\right]\right\} f_{i}^{2}\left(x_{i}(t)\right) \\
& +\sum_{i=1}^{n} \sum_{\substack{j=1 \\
j \neq i}}^{n} \lambda_{i}\left(w_{i j}+w_{i j}^{\tau}\right) f_{i}\left(x_{i}(t)\right) f_{j}\left(x_{j}(t)\right) \\
& =\frac{1}{2}\left(f_{1}\left(x_{1}(t)\right), \ldots, f_{n}\left(x_{n}(t)\right)\right) R(\varepsilon)\left(f_{1}\left(x_{1}(t)\right), \ldots, f_{n}\left(x_{n}(t)\right)\right)^{T} \text {, }
\end{aligned}
$$

where

$$
\begin{gathered}
R(\varepsilon)=\left(\begin{array}{ccc}
\eta_{1}(\varepsilon) & r_{12} & r_{13} \cdots r_{1 n} \\
r_{21} & \eta_{2}(\varepsilon) & r_{23} \cdots r_{2 n} \\
\ldots & \cdots & \cdots \\
r_{n q} & r_{n 2} & r_{n 3} \cdots \eta_{n}(\varepsilon)
\end{array}\right), \\
\eta_{i}(\varepsilon)=\lambda_{i}\left(-\frac{D_{i}}{q_{i \varepsilon}}+w_{i i}+w_{i i}^{\tau}\right)+\frac{1}{2} \sum_{j=1}^{n}\left[\left(\frac{\lambda_{i} q_{j \varepsilon} \bar{D}_{j}}{p_{j \varepsilon}}\left|w_{i j}^{\tau}\right| \tau_{i j}(t)+\frac{\lambda_{j} q_{i \varepsilon} \bar{D}_{i}}{p_{i \varepsilon}}\left|w_{j i}^{\tau}\right| \tau_{j i}(t)\right)\right] \\
+\frac{1}{2} \sum_{j=1}^{n}\left[\lambda_{i} q_{j \varepsilon} \tau_{i j}(t)\left|w_{i j}^{\tau}\right| \sum_{k=1}^{n}\left(\left|w_{j k}\right|+\left|w_{j k}^{\tau}\right|\right)\right. \\
\left.+\sum_{k=1}^{n} \lambda_{k} q_{j \varepsilon} \tau_{k j}(t)\left|w_{k j}^{\tau}\right|\left(\left|w_{j k}\right|+\left|w_{j k}^{\tau}\right|\right)\right], \quad i=1,2, \ldots, n, \\
r_{i j}=\frac{1}{2}\left\{\lambda_{i}\left(w_{i j}+w_{i j}^{\tau}\right)+\lambda_{j}\left(w_{j i}+w_{j i}^{\tau}\right)\right\}, \quad i \neq j, i, j=1,2, \ldots, n .
\end{gathered}
$$




\section{B. Stability proof}

By Appendix A, we can obtain

$$
\begin{aligned}
D^{+} V= & D^{+} V_{1}+D^{+} V_{2} \\
\leq & \sum_{i=1}^{n} \lambda_{i}\left(-\frac{\underline{D}_{i}}{q_{i \varepsilon}}+w_{i i}+w_{i i}^{\tau}\right)+\frac{1}{2} \sum_{j=1}^{n}\left[\frac{\lambda_{i} q_{j \varepsilon} \bar{D}_{j}}{p_{j \varepsilon}}\left|w_{i j}^{\tau}\right| \tau_{i j}(t)+\frac{\lambda_{j} q_{i \varepsilon} \bar{D}_{i}}{p_{i \varepsilon}}\left|w_{j i}^{\tau}\right| \tau_{j i}(t)\right] \\
& +\frac{1}{2} \sum_{j=1}^{n}\left[\lambda_{i} q_{j \varepsilon} \tau_{i j}(t)\left|w_{i j}^{\tau}\right| \sum_{k=1}^{n}\left(\left|w_{j k}\right|+\left|w_{j k}^{\tau}\right|\right)\right. \\
& \left.+\sum_{k=1}^{n} \lambda_{k} q_{j \varepsilon}\left|w_{k j}^{\tau}\right| \tau_{k j}(t)\left(\left|w_{j i}\right|+\left|w_{j i}^{\tau}\right|\right)\right] \\
& +\frac{1}{2} \sum_{j=1}^{n}\left(\lambda_{i}\left|w_{i j}+w_{i j}^{\tau}\right|+\lambda_{j}\left|w_{j i}+w_{j i}^{\tau}\right|\right) f_{i}^{2}\left(x_{i}(t)\right) \\
\leq & \sum_{\substack{j=1 \\
j}}^{n} \gamma_{i \varepsilon} f_{i}^{2}\left(x_{i}(t)\right),
\end{aligned}
$$

where

$$
\begin{aligned}
& \gamma_{i \varepsilon}=\left\{\lambda_{i}\left(-\frac{\underline{D}_{i}}{q_{i \varepsilon}}+w_{i i}+w_{i i}^{\tau}\right)+\sum_{\substack{j=1 \\
j \neq i}}^{n}\left[\frac{1}{2}\left(\frac{\lambda_{i} q_{j \varepsilon} \bar{D}_{j}}{p_{j \varepsilon}}\left|w_{i j}^{\tau}\right| \tau_{i j}(t)+\frac{\lambda_{j} q_{i \varepsilon} \bar{D}_{i}}{p_{i \varepsilon}}\left|w_{j i}^{\tau}\right| \tau_{j i}(t)\right)\right]\right. \\
& +\frac{1}{2} \sum_{j=1}^{n}\left[\lambda_{i} q_{j \varepsilon} \tau_{i j}(t)\left|w_{i j}^{\tau}\right| \sum_{k=1}^{n}\left(\left|w_{j k}\right|+\left|w_{j k}^{\tau}\right|\right)\right. \\
& \left.+q_{i \varepsilon} \sum_{k=1}^{n} \lambda_{k} \tau_{k j}(t)\left|w_{k j}^{\tau}\right|\left(\left|w_{j k}\right|+\left|w_{j k}^{\tau}\right|\right)\right] \\
& \left.\times \frac{1}{2} \sum_{\substack{j=1 \\
j \neq i}}^{n}\left(\lambda_{i}\left|w_{i j}+w_{i j}^{\tau}\right|+\lambda_{j}\left|w_{j i}+w_{j i}^{\tau}\right|\right)\right\}<0
\end{aligned}
$$

\section{Acknowledgment}

The work was supported by the Program for New Century Excellent Talents in the University, the National Nature Science and Foundation of China under Grant 60573047, the Doctorate Foundation of the Ministry of Education of China under Grant 20020611007, 
the Postdoctoral Science Foundation of China, and the Natural Science Foundation of Chongqing under Grant 8509.

\section{References}

[1] P. Baldi and A. F. Atiya, How delays affect neural dynamics and learning, IEEE Transactions on Neural Networks 5 (1994), no. 4, 612-621.

[2] K. Gopalsamy, Stability and Oscillations in Delay Differential Equations of Population Dynamics, Mathematics and Its Applications, vol. 74, Kluwer Academic, Dordrecht, 1992.

[3] K. Gopalsamy and X.-Z. He, Delay-independent stability in bi-directional associative memory networks, IEEE Transactions on Neural Networks 5 (1994), no. 6, 998-1002.

[4] J. K. Hale and S. M. Verduyn Lunel, Introduction to Functional-Differential Equations, Applied Mathematical Sciences, vol. 99, Springer, New York, 1993.

[5] J. J. Hopfield, Neurons with graded response have collective computational properties like those of two-state neurons, Proceedings of the National Academy of Sciences of the United States of America 81 (1984), no. 10, 3088-3092.

[6] X. F. Liao, K.-W. Wong, and Z. F. Wu, Asymptotic stability criteria for a two-neuron network with different time delays, IEEE Transactions on Neural Networks 14 (2003), no. 1, 222-227.

[7] X. F. Liao, G. Chen, and E. N. Sanchez, Delay-dependent exponential stability analysis of delayed neural networks: an LMI approach, Neural Networks 15 (2002), no. 7, 855-866.

[8] _ LMI-based approach for asymptotically stability analysis of delayed neural networks, IEEE Transactions on Circuits and Systems_-Part I: Fundamental Theory and Applications 49 (2002), no. 7, 1033-1039.

[9] X. F. Liao and C. G. Li, An LMI approach to asymptotical stability of multi-delayed neural networks, Physica D: Nonlinear Phenomena 200 (2005), no. 1-2, 139-155.

[10] X. F. Liao, S. W. Li, and G. Chen, Bifurcation analysis on a two-neuron system with distributed delays in the frequency domain, Neural Networks 17 (2004), no. 4, 545-561.

[11] X. F. Liao, C. G. Li, and K.-W. Wong, Criteria for exponential stability of Cohen-Grossberg neural networks, Neural Networks 17 (2004), no. 10, 1401-1414.

[12] X. F. Liao and K.-W. Wong, Global exponential stability for a class of retarded functional differential equations with applications in neural networks, Journal of Mathematical Analysis and Applications 293 (2004), no. 1, 125-148.

[13] _ Robust stability of interval bi-directional associative menmory neural networks with time delays, IEEE Transactions on Systems, Man, and Cybernetics-Part B: Cybernetics 34 (2004), no. 2, 1142-1154.

[14] X. F. Liao, K.-W. Wong, C. S. Leung, and Z. F. Wu, Hopf bifurcation and chaos in a single delayed neuron equation with non-monotonic activation function, Chaos, Solitons and Fractals 12 (2001), no. $8,1535-1547$.

[15] X. F. Liao, K.-W. Wong, and Z. F. Wu, Bifurcation analysis on a two-neuron system with distributed delays, Physica D: Nonlinear Phenomena 149 (2001), no. 1-2, 123-141.

[16] X. F. Liao, K.-W. Wong, Z. F. Wu, and G. Chen, Novel robust stability criteria for interval-delayed Hopfield neural networks, IEEE Transactions on Circuits and Systems-Part I: Fundamental Theory and Applications 48 (2001), no. 11, 1355-1359.

[17] X. F. Liao, K.-W. Wong, and S. Yang, Stability analysis for delayed cellular neural networks based on linear matrix inequality approach, International Journal of Bifurcation and Chaos 14 (2004), no. 9, 3377-3384.

[18] X. F. Liao, Z. F. Wu, and J. B. Yu, Stability switches and bifurcation analysis of a neural network with continuously delay, IEEE Transactions on Systems, Man, and Cybernetics 29 (1999), no. 6, 692-696. 
[19] X. F. Liao and J. B. Yu, Robust stability for interval Hopfield neural networks with time delay, IEEE Transactions on Neural Networks 9 (1998), no. 5, 1042-1045.

[20] X. F. Liao, J. B. Yu, and G. Chen, Novel stability conditions for cellular neural networks with time delays, International Journal of Bifurcation and Chaos 11 (2001), no. 7, 1853-1864.

[21] K. Pakdaman, C. P. Malta, C. Grotta-Ragazzo, O. Arino, and J.-F. Vibert, Transient oscillations in continuous-time excitatory ring neural networks with delay, Physical Review E. Statistical, Nonlinear, and Soft Matter Physics 55 (1997), no. 3, part B, 3234-3248.

[22] P. van den Driessche and X. Zou, Global attractivity in delayed Hopfield neural network models, SIAM Journal on Applied Mathematics 58 (1998), no. 6, 1878-1890.

Xiaofeng Liao: School of Computer and Information, Chongqing Jiaotong University, 400074 Chonqing, China

Current address: Department of Computer Science and Engineering, Chongqing University, 400030 Chongqing, China

E-mail address:xfliao@cqu.edu.cn

Xiaofan Yang: School of Computer and Information, Chongqing Jiaotong University, 400074 Chonqing, China

Current address: Department of Computer Science and Engineering, Chongqing University, 400030 Chongqing, China

E-mail address: xfyang1964@yahoo.com

Wei Zhang: Department of Computer and Modern Education Technology, Chongqing Education College, 400030 Chongqing, China

E-mail address: zhang70@cqec.net.cn 


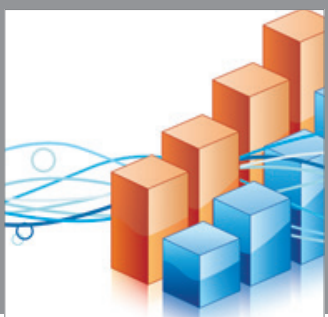

Advances in

Operations Research

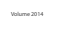

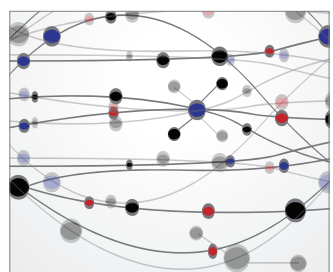

\section{The Scientific} World Journal
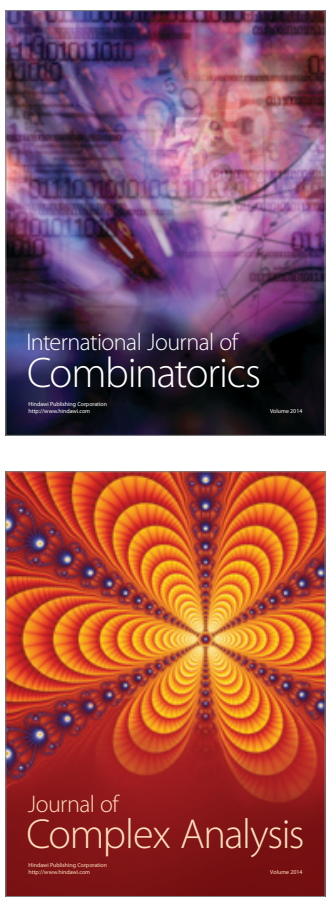

International Journal of

Mathematics and

Mathematical

Sciences
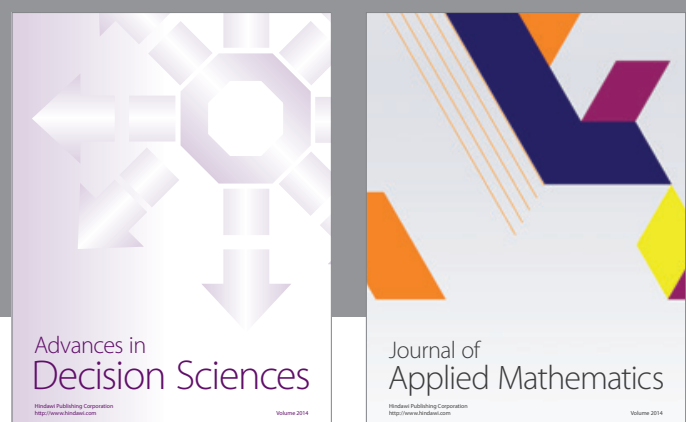

Journal of

Applied Mathematics
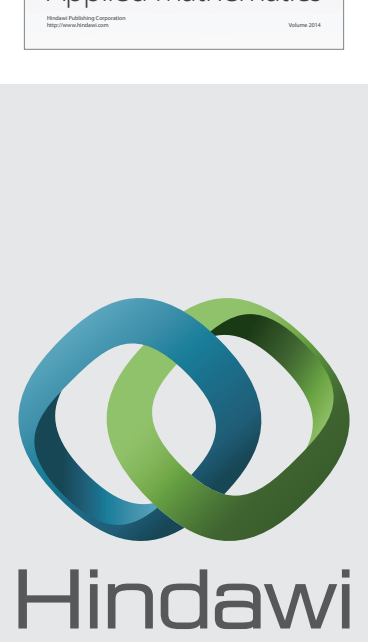

Submit your manuscripts at http://www.hindawi.com
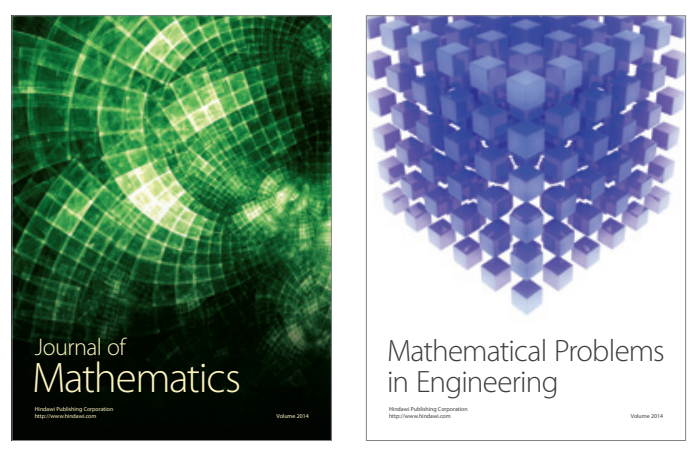

Mathematical Problems in Engineering
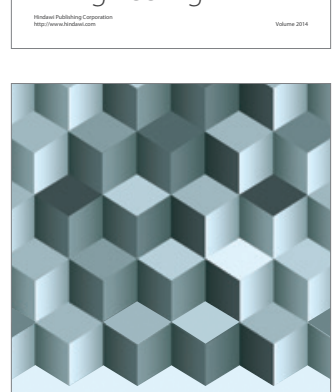

Journal of

Function Spaces
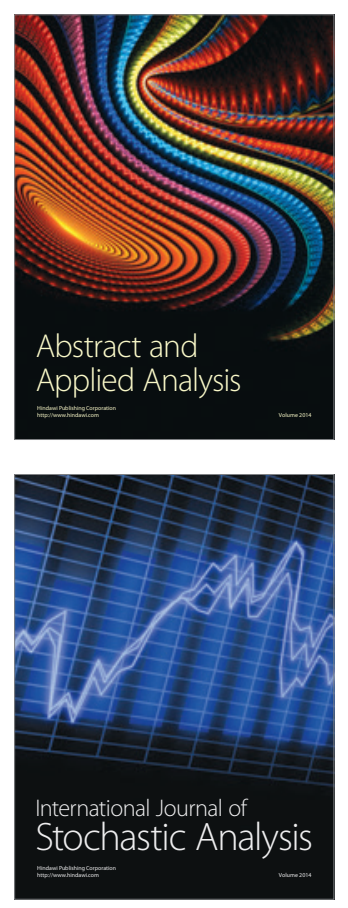

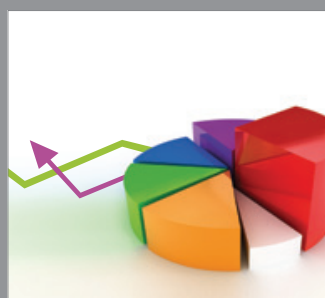

ournal of

Probability and Statistics

Promensencen
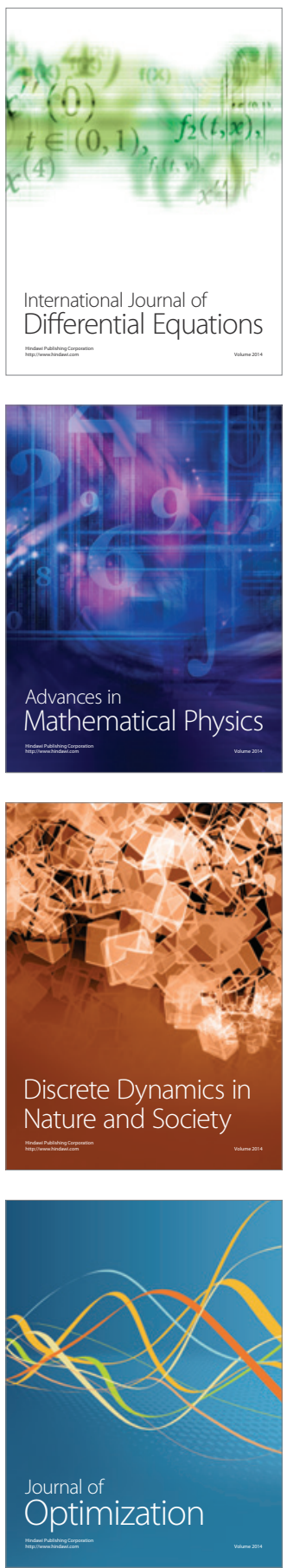